\title{
Update on Epstein-Barr virus and gastric cancer (Review)
}

\author{
AYA SHINOZAKI-USHIKU, AKIKO KUNITA and MASASHI FUKAYAMA \\ Department of Pathology, Graduate School of Medicine, The University of Tokyo, Tokyo 113-0033, Japan
}

Received October 10, 2014; Accepted December 29, 2014

DOI: 10.3892/ijo.2015.2856

\begin{abstract}
Epstein-Barr virus-associated gastric carcinoma (EBVaGC) is a distinct subtype that accounts for nearly $10 \%$ of gastric carcinomas. EBVaGC is defined by monoclonal proliferation of carcinoma cells with latent EBV infection, as demonstrated by EBV-encoded small RNA (EBER) in situ hybridization. EBVaGC has characteristic clinicopathological features, including predominance among males, a proximal location in the stomach, lymphoepithelioma-like histology and a favorable prognosis. EBVaGC belongs to latency type I or II, in which EBERs, EBNA-1, BARTs, LMP-2A and BART miRNAs are expressed. Previous studies have shown that some EBV latent genes have oncogenic properties. Recent advances in genome-wide and comprehensive molecular analyses have demonstrated that both genetic and epigenetic changes contribute to EBVaGC carcinogenesis. Genetic changes that are characteristic of EBVaGC include frequent mutations in PIK3CA and ARIDIA and amplification of JAK2 and $P D-L 1 / L 2$. Global $\mathrm{CpG}$ island hypermethylation, which induces epigenetic silencing of tumor suppressor genes, is also a unique feature of EBVaGC and is considered to be crucial for its carcinogenesis. Furthermore, post-transcriptional gene expression regulation by cellular and/or EBV-derived microRNAs has attracted considerable attention. These abnormalities result in significant alterations in gene expression related to cell proliferation, apoptosis, migration and immune signaling pathways. In the present review we highlight the latest findings on EBVaGC from clinicopathological and molecular perspectives to provide a better understanding of EBV involvement in gastric carcinogenesis.
\end{abstract}

\section{Contents}

1. Introduction

2. Definitions, epidemiology and clinical features

3. Histopathology

Correspondence to: Professor Masashi Fukayama, Department of Pathology, Graduate School of Medicine, The University of Tokyo, 7-3-1 Hongo, Bunkyo-ku, Tokyo 113-0033, Japan

E-mail: mfukayama-tky@umin.org

Key words: Epstein-Barr virus, gastric cancer
4. EBV infection in gastric epithelial cells and EBV latent genes

5. Epigenetic abnormalities

6. Somatic genomic alterations and gene expression

7. miRNA abnormalities

8. Conclusions

\section{Introduction}

Epstein-Barr virus (EBV), also known as human herpes virus 4, is a gamma-herpes virus that consists of double-stranded DNA of $\sim 170 \mathrm{~kb}$ in length. It is one of the most common human herpes viruses and infects $>90 \%$ of the world's population by adulthood and establishes lifelong, latent infections. EBV was the first virus to be associated with human malignancy, which was discovered from a Burkitt's lymphoma cell line in 1964 (1). Subsequent studies revealed that EBV caused a number of different human malignancies, such as nasopharyngeal carcinoma (NPC), Hodgkin's lymphoma, extranodal NK/T-cell lymphoma, nasal type and lymphoproliferative disorders of immunocompromised hosts (2).

In 1990, Burke et al (3), first reported the association between EBV and gastric carcinoma with characteristic lymphoepithelioma-like histology based on polymerase chain reaction (PCR) techniques. Subsequent development of in situ hybridization (ISH) techniques to detect EBV-encoded small RNAs (EBERs) facilitated the detection of EBV in cancer tissues (4,5). In gastric carcinoma cells, EBV is not integrated into the host genome but maintained as a type of plasmid called an episome. The uniformity of the numbers of terminal repeats (TRs) among EBV positive carcinoma cells reflects the clonal origin of a tumor and suggests that EBV is a causative virus for gastric carcinoma (6).

In spite of these findings, the importance of EBV in gastric carcinogenesis has long been underestimated. The reason for this is that Helicobacter Pylori (H. pylori), discovered in 1983 by Marshall and Warren, and classified as a definite carcinogen by World Health Organization in 1994, has been regarded as the major factor in almost all gastric carcinomas worldwide (7-9). Persistent infection with $H$. pylori induces atrophic gastritis and intestinal metaplasia, and subsequently leads to gastric malignancies including gastric carcinoma and extranodal marginal zone lymphoma of mucosa-associated lymphoid tissue (MALT lymphoma). In addition to accumulating more case series of EBV-associated gastric carcinoma (EBVaGC), the development of comprehensive molecular 
analyses has provided evidence that EBVaGC is a distinct subset both in terms of its clinicopathological and molecular features.

In the present review, we first describe the clinical and histological features of EBVaGC. Furthermore, we discuss recent findings on EBV associated gastric carcinogenesis by focusing on the roles of latent genes, epigenetic abnormalities, genomic alterations, and post-transcriptional regulation by cellular and viral microRNAs (miRNAs).

\section{Definitions, epidemiology and clinical features}

EBVaGC is defined by monoclonal proliferation of carcinoma cells with latent EBV infection. The gold standard for identifying EBV infection is ISH to detect EBER1, which is abundant in infected cells (up to $10^{7}$ molecules/cell). The frequency of EBV infection in gastric carcinoma ranges from 2 to $20 \%$, with a worldwide average of nearly $10 \%(10,11)$. These differences in reported frequencies may be because of geographical and environmental factors, although this remains controversial. In a meta-analysis done by Murphy et al (12), the pooled estimates of EBVaGC frequency in American, European and Asian were 9.9, 9.2 and 8.3\%, respectively, with an overall frequency of $8.7 \%$. A recent meta-analysis done by Camargo et al (13) revealed a similar overall frequency (8.2\%), although the frequencies they found were slightly higher in American (12.5\%) and European (13.9\%) cases and lower in Asian cases (7.5\%). Based on the annual incidence of gastric carcinoma (934,000 cases per year), nearly 70,000-80,000 people per year are estimated to develop EBVaGC (14).

The clinical features of EBVaGC include predominance among males and a predominant location in the proximal stomach and remnant stomach after partial gastrectomy for gastric ulcer or gastric carcinoma. Most published studies have shown an association with male gender (approximately twice as many males as females), which has been confirmed by several meta-analyses $(12,15,16)$. However, this male predominance decreases with age in terms of risk estimates (15). Studies conducted in the Americas have shown an association between EBV positive and younger age, although this was not confirmed in a meta-analysis (15-17).

Frequent EBV involvement in carcinomas of the remnant stomach has been reported in several studies, with frequencies ranging from 6 to $30 \%(10,12,16)$. EBV-positive remnant gastric carcinoma is often found at an anastomosis site in patients who underwent gastrojejunostomy and Billroth II anastomosis. Chen et al (18), investigated EBV genome polymorphisms in remnant gastric carcinoma and showed that EBV strains were similar among carcinomas in both the remnant and intact stomach. These findings suggest that repetitive injuries to the gastric mucosa, such as bile reflux and/or changes in the microenvironment, may be involved in the development of EBVaGC in the remnant stomach.

Several risk factors for developing EBVaGC have been identified (19). Eating salty or spicy foods, frequently drinking coffee and high-temperature drinks, and exposure to wood dust and/or iron filings are risk factors associated with EBVaGC. Recently, smoking was also found to be associated with EBVaGC [odds ratio (OR) of 1.5; 95\% confidence interval (CI): 1.01-2.3], after adjusting for possible confounders (20).
No significant association has been found between EBV positive and alcohol drinking (adjusted OR of 1.0). H. pylori infection, another strong risk factor for gastric carcinoma, is not a risk factor for EBVaGC, which suggests that $H$. pylori and EBV involve different carcinogenic pathways (16).

The prognostic impact of EBV infection on gastric carcinoma has long been a matter of debate. Previous studies reported that EBVaGC exhibited a lower rate of lymph node metastasis, especially during its early stage, and one study showed that survival was relatively better as compared with EBV-negative gastric carcinoma (21-24). However, several reports have shown a greater risk of death with EBVaGC, although these results were not statistically significant $(25,26)$. A recent meta-analysis provided conclusive evidence for this issue. Camargo et al (13), demonstrated that, in the largest series (to date) of 4,599 gastric carcinoma cases, EBV positive was associated with a reduced mortality rate after adjusting for the stage and other possible confounders (Hazards ratio of $0.72 ; 95 \%$ CI, 0.61-0.86).

\section{Histopathology}

By gross appearance, EBVaGC often forms ulcerated or saucer-like masses with marked thickening of the gastric wall. As noted above, a tumor is frequently located in the proximal stomach and the remnant stomach after partial gastrectomy. Multiplicity (multiple lesions occurred synchronously or metachronously in the stomach) is also a characteristic feature, as confirmed by several studies $(23,27-29)$. In its early stages, EBVaGC tends to form well-demarcated, nodular lesions in the submucosa with less fibrosis as compared with EBV-negative gastric carcinoma, and this is beneficial for endoscopic submucosal resection of a tumor (30).

Histologically, EBVaGC is subdivided into two types; lymphoepithelioma-like carcinoma (LELC)-type (Fig. 1) and conventional-type adenocarcinoma (Fig. 2), although there is a morphological continuum between these types. LELC-type is described as a poorly differentiated carcinoma with dense infiltration of lymphocytes, which resembles NPC. Because of the prominent lymphocytic infiltration, it is often difficult to identify individual carcinoma cells with routine hematoxylin and eosin (H\&E) staining. Immunohistochemistry with antibodies to cytokeratin and EBER-ISH highlight these carcinoma cells. More than $80 \%$ of gastric carcinoma cases showing LELCtype morphology are EBV-positive $(23,31)$. This histological pattern is also referred to as 'gastric carcinoma with lymphoid stroma (GCLS)' defined as carcinoma showing microalveolar, trabecular, or primitive-tubular pattern with uniformly dense and diffuse lymphoid cell infiltration, which encompasses broader morphologic variants including LELC (32).

EBVaGC with conventional-type adenocarcinoma histology shows well to moderately differentiated adenocarcinoma with variable amount of infiltrating lymphocytes, and it is classified as an intestinal type gastric carcinoma in Lauren's classification (33). Morphologically, it is almost identical to EBV-negative gastric carcinoma; therefore, EBER-ISH is necessary to identify the presence of EBV in carcinoma cells. Another subtype has been proposed called "carcinoma with Crohn's disease-like lymphoid reaction,' which is defined as a tumor accompanied by three or more lymphoid follicles 


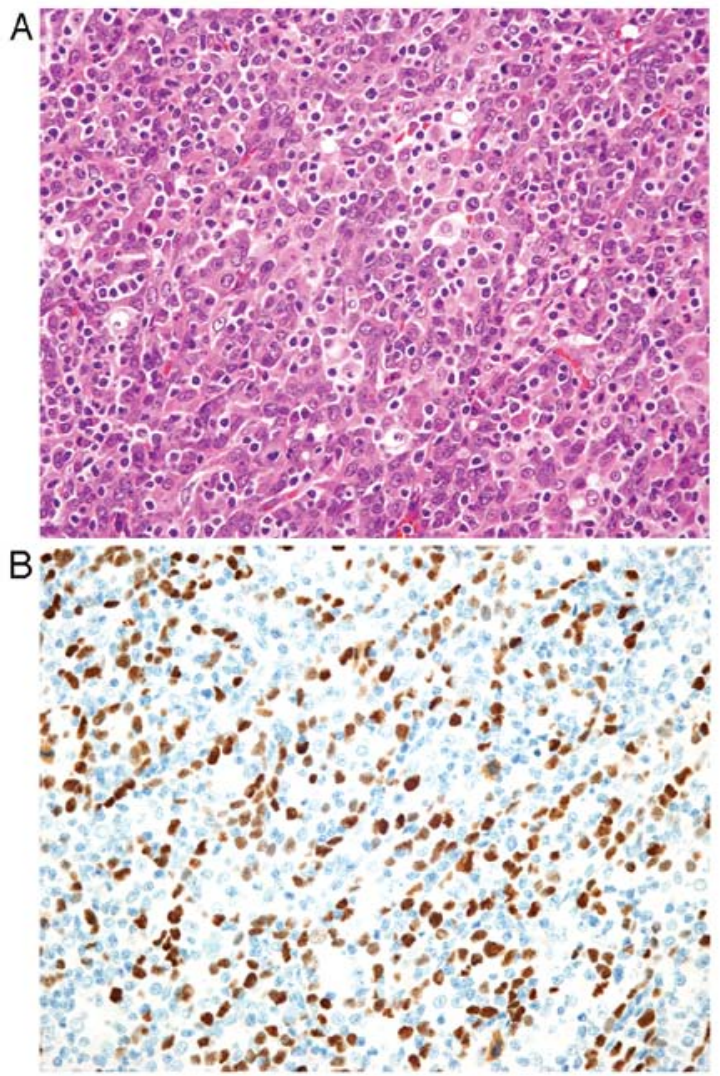

Figure 1. EBV-associated gastric carcinoma exhibiting a typical lymphoepithelioma-like carcinoma morphology. (A) H\&E staining. Poorly differentiated carcinoma with prominent lymphocytic infiltration. Scattered individual carcinoma cells are difficult to identify with routine staining (B) EBER-ISH highlights carcinoma cells (stained brown). Note the infiltrating lymphocytes are EBER-negative.

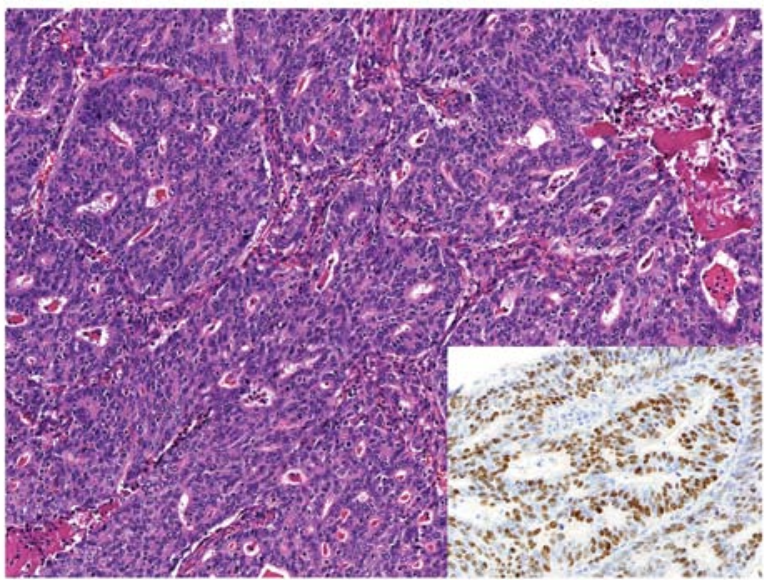

Figure 2. EBV-associated gastric carcinoma exhibiting conventional type adenocarcinoma histology. Moderately differentiated adenocarcinoma with a cribriform pattern. It is difficult to differentiate this type of carcinoma from EBV-negative one without EBER-ISH (inset).

with active germinal centers at the advancing edge of the tumor, fewer lymphocytes than tumor cells, frequent tubule or gland formation and minimal or no desmoplasia (34) (Fig. 3). This type represents a morphology intermediate between the typical LELC-type and conventional-type adenocarcinoma and could be included in GCLS.
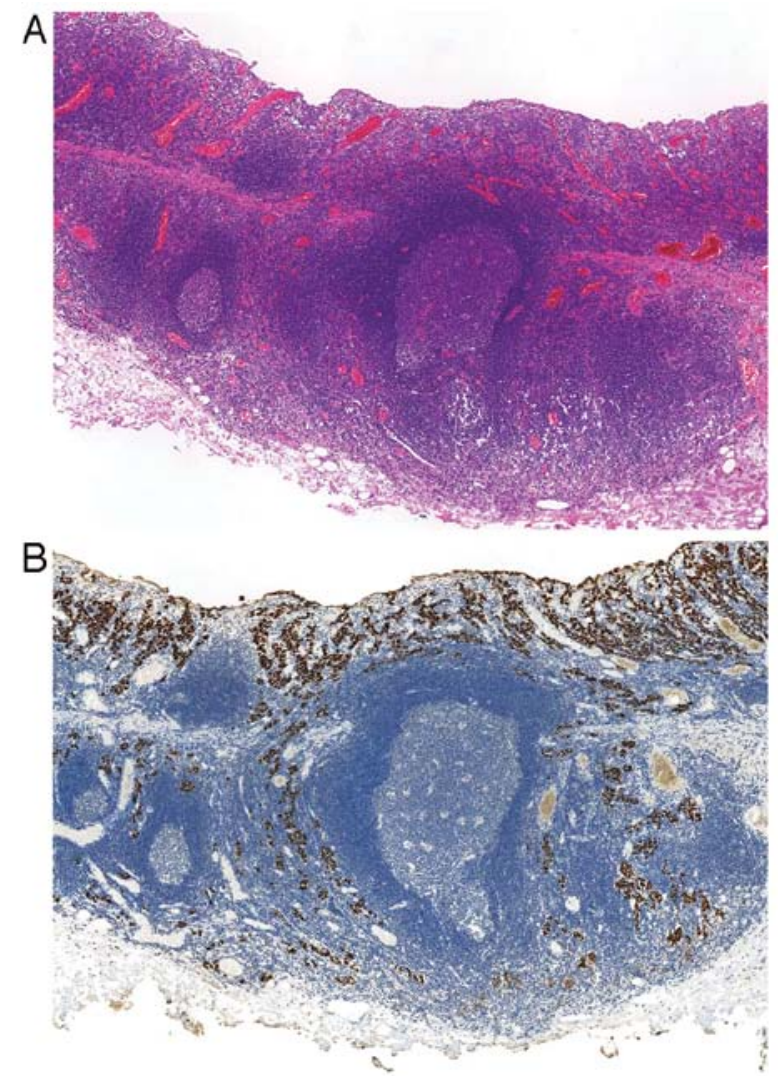

Figure 3. EBV-associated gastric carcinoma with Crohn's disease-like lymphoid reaction. (A) H\&E staining. Lymphoid follicles with well-formed germinal centers are observed in the submucosal layer. (B) EBER-ISH highlights carcinoma cells.

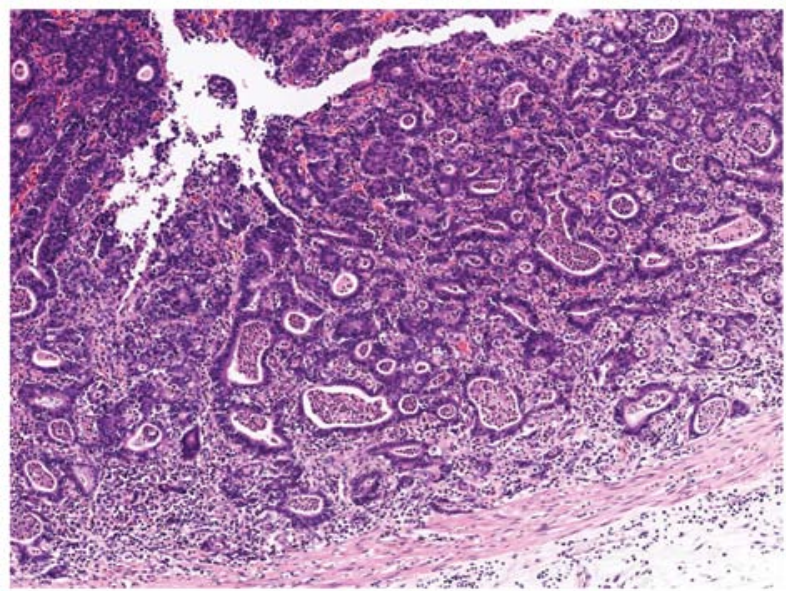

Figure 4. Lace pattern. An intramucosal lesion forms irregularly anastomosing tubules and cords, which results in a lace-like or reticular pattern at low magnification.

EBVaGC in its early stage shows a characteristic histology called a 'lace pattern' (Fig. 4). This pattern is typically observed in an intramucosal lesion, which shows irregularly anastomosing tubules and cords associated with moderate to dense lymphocytic infiltration and results in a lace-like or reticular pattern at low magnification. When this pattern is observed in biopsy specimens, EBER-ISH is recommended for diagnostic purposes (Fig. 5). 


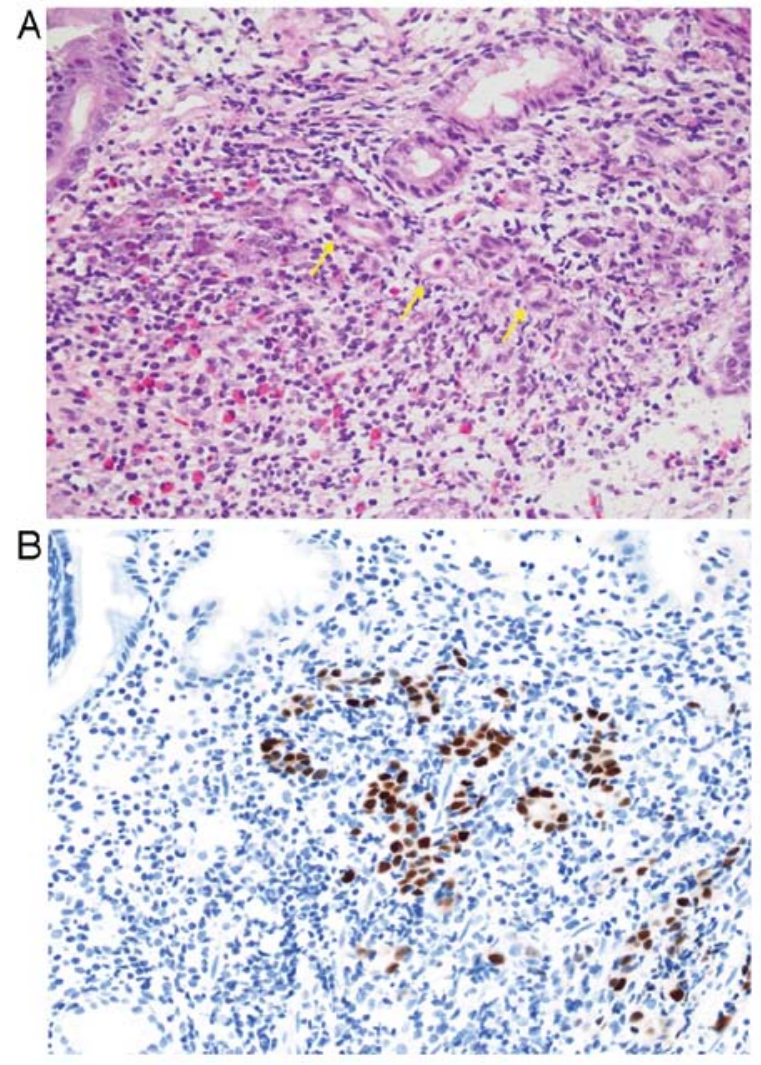

Figure 5. EBV-associated gastric carcinoma detected in a biopsy specimen (A) H\&E staining. Ill-defined tubular structures (arrows) are observed in the mucosa accompanied by dense lymphoplasmacytic and eosinophilic infiltrates. (B) EBER-ISH highlights carcinoma cells.

With regard to cell differentiation, EBVaGC displays unique features. EBVaGC immunophenotyping has shown that nearly half of the cases have gastric-type mucin (MUC5AC and MUC6) expression and the other half of cases are a null type; that is, negative for gastric-type mucin or intestinal-type markers (MUC2 and CD10) (35). Another characteristic is that $>80 \%$ of EBVaGC cases express CLDN18, while CLDN3 expression is infrequent (5\%). CLDN18 and CLDN3 belong to the claudin family that comprises tight junctions. CLDN18 expression is quite specific for the normal stomach and lung, whereas CLDN3 is expressed in the normal small and large intestines and in intestinal metaplasia, but is not expressed in the normal stomach. This suggests that the targets of EBV infection and subsequent transformation may be precursor cells that have an intrinsic differentiation potential toward the gastric cell type, but not the intestinal type. Notably, the differentiation toward gastric cell type is common to both LELC-type and other morphologic subtypes in EBVaGC, while in EBV-negative gastric carcinoma CLDN3 expression is associated with intestinal histology and CLDN18 expression with diffuse histology in Lauren's classification.

Regardless of different morphological subtypes, all carcinoma cells of EBVaGC are EBV-positive, which supports a causal role for EBV in gastric carcinogenesis. Since previous studies have not demonstrated any close associations between histological subtypes and etiological factors, anatomical location (proximal or distal), cellular phenotype, or genomic/ epigenetic alterations, it is currently unclear what causes the histological diversity of EBVaGC, which is expected to be clarified in the future studies for the better understanding of the pathogenesis of EBVaGC.

Prominent inflammatory infiltrate in the tumor is one of the characteristic features of EBVaGC. These tumor infiltrating cells are primarily lymphocytic, particularly CD8-positive or CD4-positive T cells accompanied by CD68-positive histiocytes $(10,36,37)$. In addition, infiltration of abundant B cells, plasma cells, or neutrophils is often observed and these infiltrating cells rarely masquerade as other neoplasms. We previously reported EBVaGC with prominent Mott cell (plasma cells with multiple Russell bodies) infiltration that mimicked plasma cell neoplasms (38). Infiltrating Mott cells and $\mathrm{B}$ cells were negative for immunoglobulin light chain restrictions or heavy chain rearrangements, which suggested that they were reactive in nature. Another extreme variant is EBVaGC with osteoclast-like giant cells (39). These giant cells showed a histiocytic phenotype and were considered as a reaction to gastric carcinoma.

The diversity of tumor infiltrating inflammatory cells is an important feature of EBVaGC and it is also shared by other EBV-related malignancies, such as Hodgkin's lymphoma and EBV-positive diffuse large B-cell lymphoma, which are often accompanied by numerous reactive inflammatory cells. This feature reflects the immunogenicity of EBV, and some investigators have suspected that this immune response by the host is one reason for a better prognosis. Further studies are needed to determine the detailed mechanism of an immune response against EBV-positive tumor cells in order to develop an effective treatment for this disease.

One of the interesting findings on the background of EBVaGC is that it is sometimes associated with gastritis cystica profunda (GCP), which is a relatively rare, benign lesion that is characterized by polypoid hyperplasia and cystic dilatation of the gastric glands that extend into the stomach submucosa. Choi et al (40), reported that the EBV-positive rate was significantly higher in gastric carcinoma cases with GCP (31.1\%) as compared to those without GCP (5.8\%). It has been assumed that GCP may reflect chronic inflammation in the stomach; although, it remains unclear whether the coexistence of GCP and EBVaGC is merely coincidental, or if GCP presents as a precancerous lesion.

\section{EBV infection in gastric epithelial cells and EBV latent genes}

Previous studies have investigated how EBV infection is established in gastric epithelial cells which lack the expression of viral receptor CD21 (also known as CR2) through which EBV enters B lymphocytes $(41,42)$. Since the efficiency of EBV infection is greatly improved by directly co-culturing epithelial cells with EBV-producing B lymphoblastoid cells (Akata cells) than cell-free infection, direct cell-to-cell contact with B lymphocytes is considered to be the major model of EBV infection in epithelial cells (43). Although quite rare, EBV infection is found in a small fraction of non-neoplastic gastric mucosa in a single cell or a few glands $(6,44)$, suggesting that EBV infection precedes the clonal growth of EBV-infected cells and subsequently develops carcinoma. Chronic gastritis in the background of EBVaGC might enhance the chance of 
Table I. Clinicopathological features of EBV-associated gastric carcinoma.

\begin{tabular}{|c|c|}
\hline Features & Data \\
\hline Incidence & $\sim 10 \%$ of gastric carcinoma \\
\hline Age & 60 (mean) \\
\hline Gender & Male:female $=2: 1$ \\
\hline \multirow[t]{2}{*}{ Location } & Proximal stomach (cardia and fundus) \\
\hline & Remnant stomach (after partial gastrectomy) \\
\hline \multirow[t]{3}{*}{ Gross features } & Ulcerated saucer-like mass \\
\hline & Marked thickening of the gastric wall \\
\hline & Synchronous/metachronous multiple lesions \\
\hline \multirow[t]{8}{*}{ Microscopic features } & Gastric carcinoma with lymphoid stroma (GCLS) \\
\hline & Typical lymphoepithelioma-like carcinoma (LELC) \\
\hline & Carcinoma with Crohn's disease-like lymphoid reaction \\
\hline & Conventional type adenocarcinoma \\
\hline & Lace-pattern in the mucosal layer \\
\hline & Prominent inflammatory infiltrates \\
\hline & Lymphocytes, plasma cells, histiocytes, neutrophils \\
\hline & Gastritis cystica profunda in the background \\
\hline \multirow[t]{2}{*}{ Phenotype } & Gastric mucin type or null type \\
\hline & Gastric type CLDN expression (CLDN18+, CLDN3-) \\
\hline \multirow[t]{2}{*}{ Behaviour } & Low rate of lymph node metastases \\
\hline & Better prognosis \\
\hline
\end{tabular}

Table II. Latency type in EBV-associated malignancies.

\begin{tabular}{lccc}
\hline & Latency I & Latency II & Latency III \\
\hline EBERs & + & + & + \\
EBNA-1 & + & + & + \\
EBNA-2, 3A-C, LP & + & + & + \\
LMP-1 & - & + & + \\
LMP-2A, B & - & & + \\
BARTs & - & & + \\
BART miRNAs & + & Hodgkin's lymphoma & Immunodeficiency- \\
Associated & + & Gastric carcinoma & associated lymphoma \\
malignancies & Burkitt's lymphoma & Nasopharyngeal carcinoma & + \\
& & NK/T cell lymphoma &
\end{tabular}

interaction between gastric epithelial cells and B lymphocytes, and cytokines produced by inflammatory cells might support the growth of EBV-infected gastric epithelial cells.

Most in vitro studies have utilized cell-to-cell contact method to explore the role for EBV in gastric carcinogenesis by secondarily infecting gastric carcinoma cell lines with EBV. The method is quite useful in investigating how EBV infection alters the biological nature of these cells, however, these experiments have limits in that they use cell lines already transformed to malignant cells by some factors other than EBV, which should be kept in mind when applying the results to the in vivo situation.

Once EBV infection is established in B-lymphocytes or epithelial cells, it is maintained in a latent form. Latent
EBV infection has three distinct forms that are determined by the expression patterns of latent genes. EBER-1 and 2, EBV-determined nuclear antigen (EBNA)-1, BamHI A region rightward transcripts (BARTs), and BART miRNAs (discussed later) are expressed in all latency types. In latency type II, latent membrane protein (LMP)-1, 2A and 2B are also expressed, and latency type III includes all of these latent genes along with EBNA-2, 3A, 3B, 3C and LP. These latency types differ among different EBV-associated malignancies as shown in Table II.

EBVaGC belongs to latency type I or II, in which EBERs, EBNA-1, BARTs and BART miRNAs are expressed and approximately half of EBVaGC cases express LMP-2A $(45,46)$. The expression pattern of these latent genes 
Table III. Roles of EBV latent genes in EBV-associated gastric carcinoma.

\begin{tabular}{|c|c|c|}
\hline Latent gene & Related molecules (and their downstream) & Biological function (ref.) \\
\hline EBER-1 & $\begin{array}{l}\text { IGF-1 } \\
\text { hsa-miR-200a, 200b, } \\
\text { (ZEB1, ZEB2, E-cadherin) } \\
\text { IL-6 ( STAT3, p21, p27) }\end{array}$ & $\begin{array}{l}\text { Autocrine growth (51) } \\
\text { Epithelial-to-mesenchymal transition (52) } \\
\text { Chemoresistance (53) }\end{array}$ \\
\hline EBNA-1 & $\begin{array}{l}\text { p53 } \\
\text { PML (p53, p21) }\end{array}$ & $\begin{array}{l}\text { Tumorigenicity (57) } \\
\text { Anti-apoptosis (58) }\end{array}$ \\
\hline LMP-2A & $\begin{array}{l}\text { NF- } \kappa \text { B (survivin) } \\
\text { Cyclin E1 } \\
\text { Drp-1 } \\
\text { STAT3 (DMNT-1, PTEN) } \\
\text { DMNT3b }\end{array}$ & $\begin{array}{l}\text { Anti-apoptosis }(63) \\
\text { Anti-apoptosis }(64) \\
\text { Epithelial-to-mesenchymal transition }(65) \\
\text { Epigenetic silencing of tumor suppressor genes }(66,67)\end{array}$ \\
\hline BARTs BARF1 & $\begin{array}{l}\text { Bcl-2, Bax } \\
\text { Cyclin D1 } \\
\text { NF- } \kappa \text { B/cyclin D1, p21 }{ }^{\mathrm{WAF}}\end{array}$ & $\begin{array}{l}\text { Chemoresistance (72) } \\
\text { Cell proliferation (73) } \\
\text { Cell proliferation (74) }\end{array}$ \\
\hline
\end{tabular}

is diverse among cases, and this is also true in NPCs and NK/T cell lymphomas. Two studies performed comprehensive expression profiling of viral latent and lytic transcripts in EBVaGC $(47,48)$. EBERs were the most abundant among all latent genes, followed by BARTs. LMP-2A, 2B and EBNA-1 expressions were very low. Notably, transcription of immediate early lytic genes, BZLF1 and BRLF1 was detected in some gastric carcinoma cases without subsequent progression of lytic cycle (47). Similarly, BZLF1 expression was observed in gastric carcinoma cells in vitro under long-term cultivation after EBV infection, but very few of them progressed to late lytic phase. The authors concluded that abortive lytic replication might somehow responsible for EBV genome amplification (49). These findings may provide some clues to clarify how EBV episome is maintained in EBVaGC with low/absent EBNA-1 expression.

Although LMP-1 is a well-known oncoprotein that is essential for EBV to efficiently transform resting primary $\mathrm{B}$ cells into autonomously proliferating lymphoblastoid cell lines, its expression is extremely low in EBVaGC and is usually undetectable at the protein level. To investigate the oncogenic properties of latent genes other than LMP-1, the roles of latent genes expressed in gastric carcinoma have been investigated (Table III). These findings are discussed separately in the following sections.

EBERs. EBERs are the most abundant viral transcripts found in latently EBV-infected cells and they have been shown to have various effects with regard to cell proliferation, apoptosis-resistance, production of autocrine growth factors and interactions with host proteins to enhance cellular signaling (50). However, only a few studies have investigated the roles of EBERs in gastric carcinogenesis. Iwakiri et al (51), demonstrated that EBV infection induced the expression of IGF-1 in an EBV-negative gastric carcinoma cell line, NUGC-3 and IGF-1 functioned as an autocrine growth factor. They showed that EBERs were responsible for these phenomena.
We recently reported that EBER-1 altered cellular miRNA expression to suppress E-cadherin, which resulted in an epithelial-to-mesenchymal transition (EMT) in gastric carcinoma cell line, as will be discussed later (52). Another recent report by Banerjee et al (53), showed that EBERs could upregulate IL- 6 expression and activated its downstream regulator STAT3, which resulted in downregulation of the cell cycle inhibitors p21 and p27 in a gastric carcinoma cell line, which was associated with chemoresistance. They also showed that EBERs induced the activation of pro-metastatic molecules, pFAK and pPAK1, and the downregulation of antimetastatic molecules, RhoGD1 and KAI-1, which promoted cell migration.

EBNA-1. EBNA-1 is the only viral protein that is consistently expressed in all types of EBV-associated malignancies, which is essential for the replication and stable persistence of EBV episomes. Increasing evidence has demonstrated that EBNA-1 alters the cellular environment to promote genomic instability and may have the potential to act as an oncogene (54-56). However, until recently, little was known regarding a role of EBNA-1 in gastric carcinogenesis. Cheng et al (57), reported that, the gastric cell lines SCM1 and TMC1 that were transfected with EBNA-1 had enhanced tumorigenicity and growth rates in xenografts. Another report by Sivachandran et al (58), demonstrated that AGS cells that were infected with EBV had fewer promyelocytic leukemia (PML) nuclear bodies and less PML protein than EBV-negative cells, and that these phenomena were caused by EBNA-1. These findings were also confirmed in biopsy samples. PML is a tumor suppressor protein that is associated with p53 activation. They showed that by repressing PML, EBNA-1 impaired p53 acetylation, p53-dependent p21 transcription, and apoptosis, which resulted in enhanced cell survival after DNA damage.

Considering that EBNA-1 is essential in the maintenance of EBV genome and may also act as oncogenes, EBNA-1 is one 
of the possible therapeutic targets of EBVaGC. Some previous studies have demonstrated that suppression of EBNA-1 in lymphoma cell lines inhibited cell proliferation (59-61). However, as previously mentioned, expression of EBNA-1 in EBVaGC is low, or even absent in some cases, EBNA-1targeted therapy may not be applicable to all EBVaGCs and other therapeutic approaches should be sought.

$L M P-2 A$. LMP-2A protein is expressed in about half of EBVaGC cases and has been relatively well investigated as compared with other latent genes with regard to gastric carcinogenesis. LMP-2A inhibited transforming growth factor (TGF) $\beta 1$-induced cellular apoptosis in a gastric carcinoma cell line (62). We previously reported that, the gastric cell lines that were transfected with LMP-2A had upregulated survivin expression mediated through nuclear factor $(\mathrm{NF})-\kappa \mathrm{B}$ activation, which resulted in resistance against serum deprivation-induced apoptosis (63). Similarly, Liu et al (64), showed that transfecting LMP-2A into a gastric carcinoma cell line improved cell growth and reduced apoptosis, via increased cyclin $\mathrm{E}$ expression and the proportion of cells in S phase. Another possible function of LMP-2A is activating the Notch signaling pathway, which disrupts the mitochondrial fission-fusion equilibrium by enhancing dynamin-related protein (Drp)-1 expression, which results in increased cell migration along with the overexpression of EMT markers (65).

In addition to these direct modulating effects on cell proliferation and migration, LMP-2A has a unique function inducing epigenetic changes in the host genome. LMP-2A promotes STAT3 phosphorylation, which activates the transcription of DNA methyltransferase (DNMT) 1 (66). Upregulated DNMT1 results in the epigenetic silencing of PTEN expression through the methylation of $\mathrm{CpG}$ islands in its promoter region. Zhao et al (67), demonstrated that LMP-2A caused the upregulation of DMNT3b. As will be discussed later, epigenetic changes, particularly hypermethylation of the host genome, is one of the most crucial mechanisms of EBV-induced gastric carcinogenesis, for which LMP-2A may play a part through its activation of DNMTs.

$B A R T s$. BARTs are multi-spliced transcripts that were originally discovered by cDNA library analysis of NPC xenografts and were subsequently found to be abundantly expressed in various kinds of EBV-associated malignancies. Several of these transcripts have open reading frames (ORFs), such as BARF0, BARF1, RPMS1 and A73, which possibly encode for proteins. Some of these can be artificially translated into their respective proteins in vitro, although endogenous expression of these proteins has not been completely confirmed in EBV-associated cancer tissues (68-70). Several reports on BARF1 involvement in gastric carcinogenesis have been published. The BARFI gene is expressed in nearly $100 \%$ of EBVaGC cases (71). Expression of BARF1 is also observed in NPC, while it is generally undetectable in EBV-positive B lymphocytes and lymphomas, which may be crucial in EBV-associated epithelial malignancies. Transfecting BARF1 into a gastric carcinoma cell line induces significant alterations in host gene expression, particularly those genes related to proliferation and apoptosis, and $B A R F 1$-transfected cells exhibit chemoresistance along with an increased Bcl-2-to-Bax expression ratio (72). Wiech et al (73), demonstrated that cyclin D1 was upregulated in BARF1-trasfected HaCaT cells and that cyclin D1 was overexpressed in EBVaGC cells, by immunohistochemistry. Recently, Chang et al (74), demonstrated that BARF1 protein was secreted into culture supernatants of gastric carcinoma cells that had been transfected with $B A R F 1$, using western blot analysis. These BARF1-expressing cells had increased cell proliferation that was mediated via upregulated $\mathrm{NF}-\kappa \mathrm{B} /$ cyclin D1 and reduced expression of the cell cycle inhibitor $\mathrm{p} 21^{\mathrm{WAF}}$.

\section{Epigenetic abnormalities}

A number of studies have demonstrated that epigenetic abnormalities, such as promoter hypermethylation, play crucial roles in the carcinogenesis of EBVaGC (67,75-81). Global and nonrandom $\mathrm{CpG}$ island methylation in the promoter regions of many cancer-associated genes, particularly tumor suppressor genes, is found in EBVaGC, which results in repressing the transcription of downstream genes. Initially, assessing methylation status was performed for individual genes using methylation-specific PCR (MSP). EBVaGC exhibited promoter hypermethylation in multiple genes involved in cell cycle regulation $\left(p 14^{A R F}, p 15, p 16^{I N K 4 A}\right.$ and $\left.p 73\right)$, DNA repair ( $h M L H 1, M G M T$ and GSTPl), cell adhesion and metastases (CDH1, TIMPI and TIMP3), apoptosis (DAPK and $b c l-2)$, and signal transduction (APC, PTEN and RASSF1A). The number of reported hypermethylated genes in EBVaGC continues to increase (82).

We recently performed a comprehensive analysis of the promoter methylation status of 51 gastric carcinoma cases using an Infinium HumanMethylation27 BeadChip (Illumina), which included 27,578 CpG sites covering 14,495 genes (83). Subsequent hierarchical clustering analysis demonstrated that, based on methylation status, gastric carcinoma could be subclassified into three epigenotypes, $\mathrm{EBV}^{+} /$extensively high-methylation, EBV ${ }^{-} /$high-methylation and $\mathrm{EBV}^{-} /$lowmethylation, which were characterized by different sets of methylated genes: genes specific for the $\mathrm{EBV}^{+}$type $(C X X C 4$, TIMP2 and PLXND1); highly methylated in $\mathrm{EBV}^{+}$and $\mathrm{EB}^{-} /$ high-methylation type (COL9A2, EYA1 and ZNF365); and frequently methylated in all epigenotypes ( $A M P H, S O R C 33$ and $A J A P I)$.

Genes that were methylated in EBV-negative carcinomas were also methylated in EBVaGC and 270 genes were uniquely methylated in $\mathrm{EBVaGC}$. Frequent $\mathrm{MLH} 1$ methylation (46\%) was found in the EBV-/high-methylation type, but none of the EBVaGC cases showed $M L H 1$ methylation. In addition, polycomb repressive complex (PRC)-target genes that have been reported in embryonic stem cells were enriched in genes methylated in EBV-negative types, regardless of methylation status. In contrast, aberrant methylation induced by EBV was observed not only within PRC-target genes but also within non-PRC-target genes. EBV-infection of the low-methylation type gastric cancer cell line MKN7, induced extensive methylation within 18 weeks to acquire an EBV-specific methylation epigenotype.

It is worth noting that viral latent gene expression is also suppressed by methylation. We experimentally confirmed 
Table IV. Mutations in EBV-associated gastric carcinoma.

Frequently mutated genes (ref.)

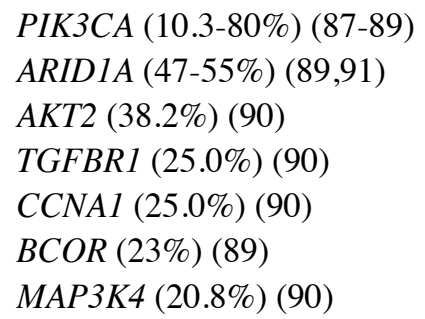

Other mutated genes $<10 \%$ )

CTNNB1(87), TP53, ITIH1, KRAS, NRAS, PLCE1, SHOC2, GIPC1, ITGA6, ITGB4, NRP1, PLEC, JAK2, CSF2RB, GHR, MPL, PTPN2, SOCS3, STAT5B, COL1A2, COL5A1, DCN, F2, IGF1, IGF2, IGFALS, IGFBP5, THBS1 (89)

that viral DNA methylation preceded the methylation of host DNA by one week (unpublished data). The methylation of viral genes might be one host defense mechanism against foreign DNA for suppressing the viral gene expression. However, this might result in other outcomes. Repressing viral latent gene expression might benefit EBV by allowing it to escape a host's immune response. In addition, excessive methylation may lead to repressing tumor suppressor genes, which ultimately could give rise to carcinogenesis.

\section{Somatic genomic alterations and gene expression}

Recent advances in genome-wide, high-throughput techniques to explore genetic alterations in cancer, such as single nucleotide polymorphism (SNP) arrays, somatic copy-number analysis, whole-exome sequencing, mRNA and miRNA sequencing, array-based DNA methylation profiling, and reverse-phase protein arrays provide new means to comprehensively investigate EBVaGC at the molecular and genetic levels. These techniques have enabled researchers to identify relatively unknown, infrequent genetic abnormalities that could not be found using conventional approaches (84-86) (Table IV).

Lee et al (87), used a high-throughput genotyping platform to determine the mutation status of 474 hotspots in 41 genes using 237 gastric adenocarcinomas, which included 58 EBVaGCs. Among these, 34 cases (14.3\%) harbored somatic mutations, 6 of which concomitantly had two different mutations. Fourteen EBVaGC cases had mutations; 6 in PIK3CA (10.3\%), 1 in p53 (1.7\%), 2 in APC (3.4\%), 1 in STK11 (1.7\%), 3 in CTNNB1 (5.2\%) and 1 in CDKN2A (1.7\%). CTNNB1 mutations were significantly more frequent in EBVaGC than in EBV-negative gastric carcinomas (one of 179 cases, $0.6 \%$ ). Frequent PIK3CA mutations were also reported in two subsequent studies; $16.7 \%$ (of $18 \mathrm{EBVaGCs)} \mathrm{in} \mathrm{a} \mathrm{report} \mathrm{by}$ Sukawa et al (88), and $80 \%$ (of 28 EBVaGCs) in a report by The Cancer Genome Atlas (TCGA) Research Network (89). A recent report by Liang et al (90), showed several newly identified mutations in $\mathrm{EBVaGC}$, including mutations in MAP3K4
(20.8\%), TGFBR1 (25.0\%), CCNA1 (25.0\%) and AKT2 (38.2\%). Among these, an $A K T 2$ mutation was associated with poor survival (90).

Another frequently mutated gene in EBVaGC is ARIDIA. ARIDIA encodes for a member of the SWI/SNF chromatin remodeling family and is currently thought to function as a tumor-suppressor gene. Wang et al (91), reported that $47 \%$ of EBVaGC cases ( 7 of 15) harbored an ARIDIA mutation by exome sequencing and $73 \%(11 / 15)$ had reduced $A R I D I A$ protein expression by immunohistochemical analysis. Clinically, ARIDIA alterations were associated with a better prognosis in a stage-independent manner. Similarly, we demonstrated that loss of ARID1A expression was frequent in EBVaGC $(23 / 67,34 \%)$, while ARID1A expression was maintained in NPCs or EBV-positive lymphomas (92). Further studies are necessary to clarify the roles of these mutations in gastric carcinogenesis by EBV.

In a recent report by the TCGA Research Network, a comprehensive molecular evaluation of 295 gastric carcinomas was performed using several different modalities, including genomic alterations, gene expression profiling and proteomic analysis. They proposed a novel molecular classification to divide gastric carcinomas into four types (89), of which EBVaGC was one. The others were: 'microsatellite instability (MSI)' characterized by hypermutation, gastric-CIMP (CpG-island methylator phenotype) and MLH1 silencing; 'genomically stable (GS),' which showed diffuse histology, CDH1 and RhoA mutations, and a CLDN18-ARHGAP fusion; and 'chromosomal instability (CIN)' with intestinal histology, a p53 mutation, marked aneuploidy and amplification of receptor tyrosine kinases.

Frequent $P I K 3 C A$ and ARIDIA mutations in EBVaGC (80 and $55 \%$, respectively) were also confirmed in that study, and frequent mutations in BCOR (BCL6 interacting co-repressor), which is a member of PRC, was also demonstrated (23\%). Similar to the results in previous reports, $p 53$ mutations were rare in EBVaGC $(82,93)$. Both PIK3CA and ARIDIA mutations were also frequent in EBV-negative, MSI-high gastric carcinoma, which was confirmed in multiple studies cited above. EBVaGC and MSI-high gastric carcinoma also shared CIMPhigh features, although epigenetic silencing of mismatch repair genes (e.g. MLH1) was rarely observed in EBVaGC, as previously noted. These findings were noted in several previous reports and indicated that $\mathrm{EBVaGC}$ had a unique carcinogenic pathway independent of MSI $(28,79,86,94)$.

Another novel finding characteristic of EBVaGC was recurrent amplification at 9p24.1 at the locus that includes $J A K 2, C D 274$ (encoding for PD-L1) and PDCD1LG2 (encoding for PD-L2). PD-L1 and PD-L2 are ligands of PD-1 that is expressed on T cells, B cells, monocytes and natural killer cells, as well as tumor infiltrating lymphocytes. Upon ligation with PD-L1 and PD-L2, PD-1 suppresses downstream PI3K and Akt signaling, which results in inhibiting $\mathrm{T}$ cell proliferation. Some malignancies have been reported to have high PD-L1 expression levels, which was associated with an aggressive behavior and poor prognosis (95). Blocking the interaction between PD-1 and PD-L1/L2 could augment an antitumor immune response, and clinical trials to investigate the efficacy of immunotherapy by targeting these molecules are under way (96). 
Table V. The roles of EBV miRNAs in EBV-associated malignancies.

\begin{tabular}{|c|c|c|c|}
\hline Name & Targets in EBV & Targets in host cells & Related malignancies (ref.) \\
\hline miR-BHRF1-1 & & GUF1, SCRN1 & Lymphoma (126) \\
\hline \multirow[t]{3}{*}{ miR-BART1-5p } & LMP-1 & & NPC (127) \\
\hline & & CLEC2D, LU75, & \\
\hline & & SP100, DICER1, MICB & Lymphoma (126) \\
\hline miR-BART1-3p & & CXCL11 & Lymphoma (119) \\
\hline miR-BART2-5p & BALF5 & & Lymphoma (128) \\
\hline \multirow[t]{2}{*}{ miR-BART3-3p } & & DICER1, MICB & Lymphoma (126) \\
\hline & & IPO7 & Lymphoma (129) \\
\hline \multirow[t]{2}{*}{ miR-BART5-5p } & LMP-1 & & Lymphoma (116) \\
\hline & & PUMA & NPC, GC (107) \\
\hline \multirow[t]{2}{*}{ miR-BART6-5p } & LMP-1 & & NPC (127) \\
\hline & & DICER1 & Lymphoma, NPC (130) \\
\hline miR-BART6-3p & & IL6R, PTEN & Lymphoma (131) \\
\hline \multirow[t]{2}{*}{ miR-BART9-3p } & LMP-1 & & Lymphoma (132) \\
\hline & & CDH1 & NPC (133) \\
\hline miR-BART10-3p & BHRF1 & & Lymphoma (116) \\
\hline miR-BART11-5p & & EBF1 & Lymphoma (134) \\
\hline miR-BART13-3p & & CAPRIN2 & Lymphoma (116) \\
\hline \multirow[t]{2}{*}{ miR-BART15-3p } & & NLRP3 & Lymphoma (135) \\
\hline & & BRUCE & GC (106) \\
\hline \multirow[t]{2}{*}{ miR-BART16 } & LMP-1 & & NPC (127) \\
\hline & & TOMM22 & Lymphoma (129) \\
\hline miR-BART17-5p & LMP-1 & & NPC (127) \\
\hline miR-BART18-5p & & MAP3K2 & Lymphoma (121) \\
\hline miR-BART19-3p & LMP-1 & & Lymphoma (116) \\
\hline \multirow[t]{2}{*}{$\operatorname{miR}-B A R T 20-5 p$} & BZLF1, BRLF1 & & GC (136) \\
\hline & & $\mathrm{TBX} 21$ & Lymphoma (137) \\
\hline miR-BART22 & LMP-2A & & NPC (138) \\
\hline miR-BART miRNAs & & BIM & GC (113) \\
\hline
\end{tabular}

NPC, nasopharyngeal carcinoma; GC, gastric carcinoma.

Gene expression profiling and proteomic analysis have revealed activation in immune cell signaling and mitotic pathways, along with inactivation of the HIF-1 $\alpha$ transcription factor network in EBVaGC $(48,89,97,98)$. In the report by the TCGA Research Network, EBVaGC exhibited high expression of CXCL11, CXCL9, CXCL17, IDO1, CXCL10, UGT2A3, LOC400043, CAMK2N2, DKK1 and MIA, and low expression of CLDN3, PPP1R1B, REG4, CDH17, TFF3, SCNN1A, FUT3, MUC3A, KR7 and WFDC2 as compared to other types of gastric cancers (89). Enhanced IL-12 mediated signaling signatures were highly characteristic of EBVaGC. In the report by Kim et al (98), genes associated with cytokine activities, immune response, leukocyte migration, hormone secretion and cholesterol transport for lipoprotein clearance were deregulated in EBVaGC. Along with the evidence for PD-L1/L2 overexpression, modulating immune cell signaling may have therapeutic effects on EBVaGC (98-100).

\section{7. miRNA abnormalities}

While genetic and epigenetic alterations induce the upregulation or downregulation of cancer-associated genes at the transcriptional level, miRNAs are novel, post-transcriptional regulators of gene expression. A miRNA is a small, non-coding RNA molecule 22 nucleotides in length and is coded in the introns or exons of encoding genes. A miRNA precursor is processed from these transcripts and is subsequently processed by Drosha and Dicer to a mature form. Mature miRNA interacts with the $3^{\prime}$ untranslated region (UTR) of a target mRNA and represses its translation. To date, $>2,600$ human miRNAs (cellular miRNAs) have been archived in miRBase (http://www.mirbase.org). An increasing number of studies have shown that the dysregulation of certain miRNAs induces carcinogenesis in various organs. Similar to oncogenes and tumor suppressor genes, miRNAs associated with carcinogenesis are called oncomiRs and anti-oncomiRs. Alterations in 


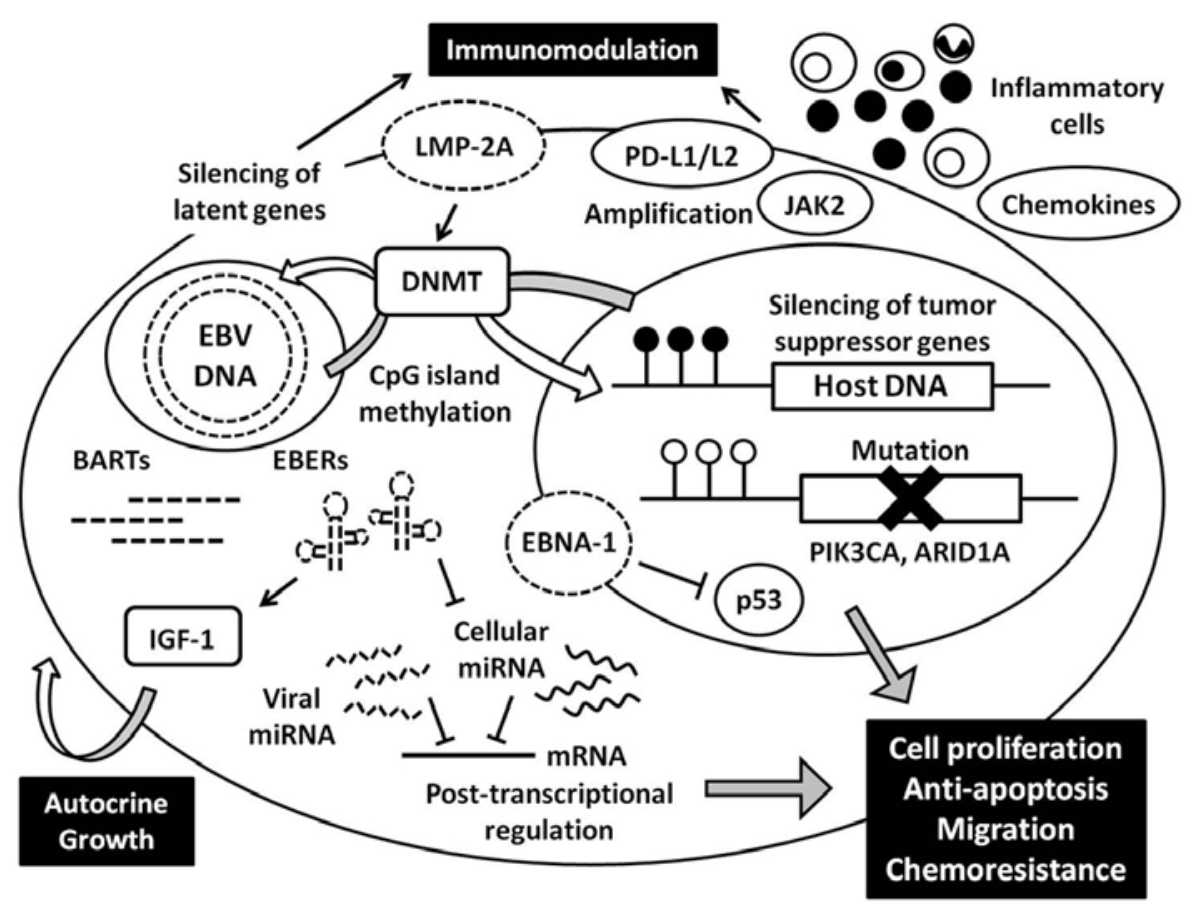

Figure 6. Schematic outlining the oncogenic properties of EBV in gastric carcinoma.

cellular miRNAs in EBVaGC have not been intensively investigated. We previously reported that two cellular miRNAs, hsa-miR-200a and hsa-miR-200b, were downregulated in EBVaGC both in tissue samples and in cell lines (52). These miRNAs targeted the transcription repressors ZEB1 and ZEB2, which regulate E-cadherin expression. Downregulation of these miRNAs ultimately reduced E-cadherin expression and triggered the epithelial-to-mesenchymal transition. EBV latent genes, BARF0, EBNA-1 and EBERs, cooperatively suppressed hsa-miR-200a and 200b expression in cell lines; while reduced ZEB 1, ZEB2 and E-cadherin expression was significant only in EBERs-transfected cells.

Viral genomes also encode for miRNAs and EBV was the first virus in which viral miRNAs were found (101-103). To date, $25 \mathrm{EBV}$ miRNA precursors and 44 mature EBV miRNAs have been registered in miRBase. EBV-encoded miRNAs fall into two major clusters: BHRF-1 and BART. The BHRF-1 cluster contains four mature miRNAs that are expressed only in lytically infected cells or cells with latency type III infections. The BART cluster is located in the non-coding region of BARTs, and is further subdivided into subclusters 1 and 2, which include 38 mature EBV miRNAs in total, and the miRNAs ebv-miR-BART2-5p and ebv-miR-BART2-3p are located downstream of these two clusters.

Several studies profiled EBV-encoded miRNA expression in EBV-associated malignancies, including NPC and Diffuse large B cell lymphoma (DLBCL), and showed that specific viral miRNAs played roles in carcinogenesis (Table V) (104-121). Several reports investigated the expression of viral miRNAs in EBVaGC tissue samples and cell lines (97,112,122-125). EBV miRNAs were variably expressed in EBVaGC cells, among which ebv-miR-BART1-3p, 2-5p, 3-3p, 4-5p, 5-5p, 7-3p, $9-3 p, 10-3 p, 17-5 p$ and $18-5 p$ were expressed at relatively high levels. The ebv-miR-BART7-3p expression level was consis- tently high in other EBV-associated malignancies, although its function has not been determined. A recent study by Marquitz et al (123), reported the expression profiles of cellular and viral miRNAs in EBV-infected AGS cells. By sequencing small RNA libraries created from these cells, they showed that EBV miRNA constituted $15 \%$ of total miRNAs, and that the remainder was derived from host cells. miRNA PCR array analysis revealed that let-7 family members, miR-200 family members, and several human miRNAs were downregulated by EBV infection. In addition, EBNA-1 transfection reduced hsa-miR-143 expression in AGS cells. Another report by the same group showed that gene expression changes induced by EBV infection of AGS cells were highly enriched for genes involved in cell motility and transformation pathways, and that these genes were potentially targeted by viral miRNAs (97).

Viral miRNA involvement in EBVaGC remains largely unknown. We performed comprehensive profiling of viral miRNA expression in tissue samples of EBVaGC and identified frequently expressed viral miRNAs. In silico analysis provided potential targets of these miRNAs, including genes associated with cell proliferation, apoptosis, and migration, and the direct interaction of these target genes and specific viral miRNAs were validated in vitro (unpublished data). Further studies to clarify the roles of cellular and viral miRNAs and the regulatory mechanisms of these molecules by EBV and host cells will be needed to completely understand the carcinogenic mechanisms involved in EBVaGC.

\section{Conclusions}

EBVaGC is a distinct subtype of gastric carcinoma with regard to both its clinicopathological and molecular features. Recent advances in comprehensive genome-wide analysis have provided novel findings regarding the genetic and epigenetic 
abnormalities that are unique to $\mathrm{EBVaGC}$, and these various factors cooperate to develop carcinoma (Fig. 6). Global and non-random $\mathrm{CpG}$ island hypermethylation is characteristic feature of EBVaGC, and epigenetic silencing of various genes, especially tumor suppressor genes, play a key role in carcinogenesis. Furthermore, increased activation of DNA methyltransferase by LMP-2A also induces hypermethylation of EBV genome itself, resulting in limited expression of latent genes, which may benefit in escaping from immune response by the host. Viral specific transcripts including latent genes and miRNAs have oncogenic properties such as increased cell proliferation and motility, anti-apoptotic effect, and chemoresistance, which help tumor progression. Although EBVaGC is relatively genomically stable, frequent mutations in the $P I K 3 C$ and $A R I D I A$ genes are found; and the roles of these mutations in carcinogenesis are expected to be clarified in the future studies. Furthermore, there remain questions regarding how and when these mutations occur, what triggers hypermethylation, and how host cells regulate the transcription of viral genes. Finally, the interaction between carcinoma and inflammatory cells is another key to understand its carcinogenesis, which will also benefit the development of disease-specific therapies.

\section{References}

1. Epstein MA, Achong BG and Barr YM: Virus particles in cultured lymphoblasts from Burkitt's lymphoma. Lancet 1: 702-703, 1964

2. Young LS and Rickinson AB: Epstein-Barr virus: 40 years on. Nat Rev Cancer 4: 757-768, 2004.

3. Burke AP, Yen TS, Shekitka KM and Sobin LH: Lymphoepithelial carcinoma of the stomach with Epstein-Barr virus demonstrated by polymerase chain reaction. Mod Pathol 3: 377-380, 1990.

4. Shibata D, Tokunaga M, Uemura Y, Sato E, Tanaka S and Weiss LM: Association of Epstein-Barr virus with undifferentiated gastric carcinomas with intense lymphoid infiltration Lymphoepithelioma-like carcinoma. Am J Pathol 139: 469-474, 1991.

5. Shibata D and Weiss LM: Epstein-Barr virus-associated gastric adenocarcinoma. Am J Pathol 140: 769-774, 1992.

6. Fukayama M, Hayashi Y, Iwasaki Y, et al: Epstein-Barr virusassociated gastric carcinoma and Epstein-Barr virus infection of the stomach. Lab Invest 71: 73-81, 1994.

7. Marshall BJ and Warren JR: Unidentified curved bacilli in the stomach of patients with gastritis and peptic ulceration. Lancet 1: $1311-1315,1984$

8. Nomura A, Stemmermann GN, Chyou PH, Kato I, PerezPerez GI and Blaser MJ: Helicobacter pylori infection and gastric carcinoma among Japanese Americans in Hawaii. N Engl J Med 325: 1132-1136, 1991.

9. Parsonnet J, Friedman GD, Vandersteen DP, et al: Helicobacter pylori infection and the risk of gastric carcinoma. N Engl J Med 325: 1127-1131, 1991.

10. Fukayama $M$ and Ushiku T: Epstein-Barr virus-associated gastric carcinoma. Pathol Res Pract 207: 529-537, 2011.

11. Chen JN, He D, Tang F and Shao CK: Epstein-Barr virusassociated gastric carcinoma: a newly defined entity. J Clin Gastroenterol 46: 262-271, 2012.

12. Murphy G, Pfeiffer R, Camargo MC and Rabkin CS: Metaanalysis shows that prevalence of Epstein-Barr virus-positive gastric cancer differs based on sex and anatomic location. Gastroenterology 137: 824-833, 2009.

13. Camargo MC, Kim WH, Chiaravalli AM, et al: Improved survival of gastric cancer with tumour Epstein-Barr virus positivity: an international pooled analysis. Gut 63: 236-243, 2014.

14. Boyle P and Levin B: Stomach Cancer. IARC Press, Lyon, 2008.

15. Camargo MC, Murphy G, Koriyama C, et al: Determinants of Epstein-Barr virus-positive gastric cancer: an international pooled analysis. Br J Cancer 105: 38-43, 2011.
16. Lee JH, Kim SH, Han SH, An JS, Lee ES and Kim YS: Clinicopathological and molecular characteristics of EpsteinBarr virus-associated gastric carcinoma: a meta-analysis. J Gastroenterol Hepatol 24: 354-365, 2009.

17. Truong CD, Feng W, Li W, et al: Characteristics of Epstein-Barr virus-associated gastric cancer: a study of 235 cases at a comprehensive cancer center in USA. J Exp Clin Cancer Res 28: 14, 2009.

18. Chen JN, Jiang Y, Li HG, et al: Epstein-Barr virus genome polymorphisms of Epstein-Barr virus-associated gastric carcinoma in gastric remnant carcinoma in Guangzhou, southern China, an endemic area of nasopharyngeal carcinoma. Virus Res 160: 191-199, 2011.

19. Koriyama C, Akiba S, Minakami Y and Eizuru Y: Environmental factors related to Epstein-Barr virus-associated gastric cancer in Japan. J Exp Clin Cancer Res 24: 547-553, 2005.

20. Camargo MC, Koriyama C, Matsuo K, et al: Case-case comparison of smoking and alcohol risk associations with Epstein-Barr virus-positive gastric cancer. Int J Cancer 134: 948-953, 2014.

21. van Beek J,zurHausen A, Klein Kranenbarg E, et al: EBV-positive gastric adenocarcinomas: a distinct clinicopathologic entity with a low frequency of lymph node involvement. J Clin Oncol 22: 664-670, 2004

22. Tokunaga $M$ and Land CE: Epstein-Barr virus involvement in gastric cancer: biomarker for lymph node metastasis. Cancer Epidemiol Biomarkers Prev 7: 449-450, 1998.

23. Matsunou H, Konishi F, Hori H, et al: Characteristics of EpsteinBarr virus-associated gastric carcinoma with lymphoid stroma in Japan. Cancer 77: 1998-2004, 1996.

24. Song HJ, Srivastava A, Lee J, et al: Host inflammatory response predicts survival of patients with Epstein-Barr virus-associated gastric carcinoma. Gastroenterology 139: 84-92.e82, 2010.

25. Koriyama C, Akiba S, Itoh T, et al: Prognostic significance of Epstein-Barr virus involvement in gastric carcinoma in Japan. Int J Mol Med 10: 635-639, 2002.

26. Kijima Y, Ishigami S, Hokita S, et al: The comparison of the prognosis between Epstein-Barr virus (EBV)-positive gastric carcinomas and EBV-negative ones. Cancer Lett 200: 33-40, 2003.

27. Tokunaga M, Land CE, Uemura Y, Tokudome T, Tanaka S and Sato E: Epstein-Barr virus in gastric carcinoma. Am J Pathol 143: 1250-1254, 1993 .

28. Chang MS, Lee HS, Kim HS, et al: Epstein-Barr virus and microsatellite instability in gastric carcinogenesis. J Pathol 199: 447-452, 2003

29. Kaizaki Y, Hosokawa O, Sakurai S and Fukayama M: EpsteinBarr virus-associated gastric carcinoma in the remnant stomach: de novo and metachronous gastric remnant carcinoma. J Gastroenterol 40: 570-577, 2005.

30. Lee JY, Kim KM, Min BH, Lee JH, Rhee PL and Kim JJ: Epstein-Barr virus-associated lymphoepithelioma-like early gastric carcinomas and endoscopic submucosal dissection: case series. World J Gastroenterol 20: 1365-1370, 2014.

31. Nakamura S, Ueki T, Yao T, Ueyama T and Tsuneyoshi M: Epstein-Barr virus in gastric carcinoma with lymphoid stroma. Special reference to its detection by the polymerase chain reaction and in situ hybridization in 99 tumors, including a morphologic analysis. Cancer 73: 2239-2249, 1994

32. Watanabe H, Enjoji $M$ and Imai T: Gastric carcinoma with lymphoid stroma. Its morphologic characteristics and prognostic correlations. Cancer 38: 232-243, 1976.

33. Lauren P: The two histological main types of gastric carcinoma: diffuse and so-called intestinal-type carcinoma. An attempt at a histo-clinical classification. Acta Pathol Microbiol Scand 64: 31-49, 1965 .

34. Song HJ and Kim KM: Pathology of epstein-barr virus-associated gastric carcinoma and its relationship to prognosis. Gut Liver 5: 143-148, 2011.

35. Shinozaki A, Ushiku T, Morikawa T, et al: Epstein-Barr virus-associated gastric carcinoma: a distinct carcinoma of gastric phenotype by claudin expression profiling. J Histochem Cytochem 57: 775-785, 2009.

36. van Beek J, zur Hausen A, Snel SN, et al: Morphological evidence of an activated cytotoxic T-cell infiltrate in EBV-positive gastric carcinoma preventing lymph node metastases. Am J Surg Pathol 30: 59-65, 2006

37. Kuzushima K, Nakamura S, Nakamura T, et al: Increased frequency of antigen-specific $\mathrm{CD}^{+}$cytotoxic $\mathrm{T}$ lymphocytes infiltrating an Epstein-Barr virus-associated gastric carcinoma. J Clin Invest 104: 163-171, 1999. 
38. Shinozaki A, Ushiku T and Fukayama M: Prominent Mott cell proliferation in Epstein-Barr virus-associated gastric carcinoma. Hum Pathol 41: 134-138, 2009.

39. Ushiku T, Shinozaki A, Uozaki H, et al: Gastric carcinoma with osteoclast-like giant cells. Lymphoepithelioma-like carcinoma with Epstein-Barr virus infection is the predominant type. Pathol Int 60: 551-558, 2010.

40. Choi MG, Jeong JY, Kim KM, et al: Clinical significance of gastritis cystica profunda and its association with Epstein-Barr virus in gastric cancer. Cancer 118: 5227-5233, 2012.

41. Tsao SW, Tsang CM, Pang PS, Zhang G, Chen H and Lo KW: The biology of EBV infection in human epithelial cells. Semin Cancer Biol 22: 137-143, 2012.

42. Rickinson $A B$ : Co-infections, inflammation and oncogenesis: future directions for EBV research. Semin Cancer Biol 26: 99-115, 2014

43. Imai S, Nishikawa $\mathbf{J}$ and Takada K: Cell-to-cell contact as an efficient mode of Epstein-Barr virus infection of diverse human epithelial cells. J Virol 72: 4371-4378, 1998.

44. Hayashi K, Teramoto N, Akagi T, Sasaki Y and Suzuki T: In situ detection of Epstein-Barr virus in the gastric glands with intestinal metaplasia. Am J Gastroenterol 91: 1481, 1996.

45. Sugiura M, Imai S, Tokunaga M, et al: Transcriptional analysis of Epstein-Barr virus gene expression in EBV-positive gastric carcinoma: unique viral latency in the tumour cells. Br J Cancer 74: 625-631, 1996

46. Luo B, Wang Y, Wang XF, et al: Expression of Epstein-Barr virus genes in EBV-associated gastric carcinomas. World $\mathrm{J}$ Gastroenterol 11: 629-633, 2005.

47. Strong MJ, Xu G, Coco J, et al: Differences in gastric carcinoma microenvironment stratify according to EBV infection intensity: implications for possible immune adjuvant therapy. PLoS Pathog 9: e1003341, 2013

48. Tang W, Morgan DR, Meyers MO, et al: Epstein-barr virus infected gastric adenocarcinoma expresses latent and lytic viral transcripts and has a distinct human gene expression profile. Infect Agent Cancer 7: 21, 2012.

49. Shannon-Lowe C, Adland E, Bell AI, Delecluse HJ, Rickinson AB and Rowe M: Features distinguishing Epstein-Barr virus infections of epithelial cells and B cells: viral genome expression, genome maintenance, and genome amplification. J Virol 83: 7749-7760, 2009.

50. Iwakiri D and Takada K: Role of EBERs in the pathogenesis of EBV infection. Adv Cancer Res 107: 119-136, 2010.

51. Iwakiri D, Eizuru Y, Tokunaga M and Takada K: Autocrine growth of Epstein-Barr virus-positive gastric carcinoma cells mediated by an Epstein-Barr virus-encoded small RNA. Cancer Res 63: 7062-7067, 2003.

52. Shinozaki A, Sakatani T, Ushiku T, et al: Downregulation of microRNA-200 in EBV-associated gastric carcinoma. Cancer Res 70: 4719-4727, 2010.

53. Banerjee AS, Pal AD and Banerjee S: Epstein-Barr virus-encoded small non-coding RNAs induce cancer cell chemoresistance and migration. Virology 443: 294-305, 2013.

54. Gruhne B, Sompallae R, Marescotti D, Kamranvar SA, Gastaldello S and Masucci MG: The Epstein-Barr virus nuclear antigen-1 promotes genomic instability via induction of reactive oxygen species. Proc Natl Acad Sci USA 106: 2313-2318, 2009.

55. Lu J, Murakami M, Verma SC, et al: Epstein-Barr Virus nuclear antigen 1 (EBNA1) confers resistance to apoptosis in EBV-positive B-lymphoma cells through up-regulation of survivin. Virology 410: 64-75, 2011.

56. Saridakis V, Sheng Y, Sarkari F, et al: Structure of the p53 binding domain of HAUSP/USP7 bound to Epstein-Barr nuclear antigen 1 implications for EBV-mediated immortalization. Mol Cell 18: 25-36, 2005.

57. Cheng TC, Hsieh SS, Hsu WL, Chen YF, Ho HH and Sheu LF: Expression of Epstein-Barr nuclear antigen 1 in gastric carcinoma cells is associated with enhanced tumorigenicity and reduced cisplatin sensitivity. Int J Oncol 36: 151-160, 2010.

58. Sivachandran N, Dawson CW, Young LS, Liu FF, Middeldorp J and Frappier L: Contributions of the Epstein-Barr virus EBNA1 protein to gastric carcinoma. J Virol 86: 60-68, 2012.

59. Yin Q and Flemington EK: siRNAs against the Epstein Barr virus latency replication factor, EBNA1, inhibit its function and growth of EBV-dependent tumor cells. Virology 346: 385-393, 2006.

60. Hong M, Murai Y, Kutsuna T, et al: Suppression of Epstein-Barr nuclear antigen 1 (EBNA1) by RNA interference inhibits proliferation of EBV-positive Burkitt's lymphoma cells. J Cancer Res Clin Oncol 132: 1-8, 2006
61. Ian MX, Lan SZ, Cheng ZF, Dan H and Qiong LH: Suppression of EBNA1 expression inhibits growth of EBV-positive NK/T cell lymphoma cells. Cancer Biol Ther 7: 1602-1606, 2008.

62. Fukuda M, Ikuta K, Yanagihara K, et al: Effect of transforming growth factor-betal on the cell growth and Epstein-Barr virus reactivation in EBV-infected epithelial cell lines. Virology 288: 109-118, 2001.

63. Hino R, Uozaki H, Inoue Y, et al: Survival advantage of EBV-associated gastric carcinoma: survivin up-regulation by viral latent membrane protein 2A. Cancer Res 68: 1427-1435, 2008.

64. Liu X, Gao Y, Luo B and Zhao Y: Construction and antiapoptosis activities of recombinant adenoviral Expression vector carrying EBV latent membrane protein 2A. Gastroenterol Res Pract 2011: 182832,2011

65. Pal AD, Basak NP, Banerjee AS and Banerjee S: Epstein-Barr virus latent membrane protein-2A alters mitochondrial dynamics promoting cellular migration mediated by Notch signaling pathway. Carcinogenesis 35: 1592-1601, 2014.

66. Hino R, Uozaki H, Murakami N, et al: Activation of DNA methyltransferase 1 by EBV latent membrane protein $2 \mathrm{~A}$ leads to promoter hypermethylation of PTEN gene in gastric carcinoma. Cancer Res 69: 2766-2774, 2009.

67. Zhao J, Liang Q, Cheung KF, et al: Genome-wide identification of Epstein-Barr virus-driven promoter methylation profiles of human genes in gastric cancer cells. Cancer 119: 304-312, 2013.

68. Al-Mozaini M, Bodelon G, Karstegl CE, Jin B, Al-Ahdal M and Farrell PJ: Epstein-Barr virus BART gene expression. J Gen Virol 90: 307-316, 2009.

69. Thornburg NJ, Kusano S and Raab-Traub N: Identification of Epstein-Barr virus RK-BARF0-interacting proteins and characterization of expression pattern. J Virol 78: 12848-12856, 2004.

70. Hoebe EK, Le Large TY, Greijer AE and Middeldorp JM: BamHI-A rightward frame 1, an Epstein-Barr virus-encoded oncogene and immune modulator. Rev Med Virol 23: 367-383, 2013.

71. zur Hausen A, Brink AA, Craanen ME, Middeldorp JM, Meijer CJ and van den Brule AJ: Unique transcription pattern of Epstein-Barr virus (EBV) in EBV-carrying gastric adenocarcinomas: expression of the transforming BARF1 gene. Cancer Res 60: 2745-2748, 2000.

72. Wang Q, Tsao SW, Ooka T, et al: Anti-apoptotic role of BARF1 in gastric cancer cells. Cancer Lett 238: 90-103, 2006.

73. Wiech T, Nikolopoulos E, Lassman S, et al: Cyclin D1 expression is induced by viral BARF1 and is overexpressed in EBV-associated gastric cancer. Virchows Arch 452: 621-627, 2008.

74. Chang MS, Kim DH, Roh JK, et al: Epstein-Barr virus-encoded BARF1 promotes proliferation of gastric carcinoma cells through regulation of NF-kappaB. J Virol 87: 10515-10523, 2013.

75. Kaneda A, Matsusaka K, Aburatani H and Fukayama M: EpsteinBarr virus infection as an epigenetic driver of tumorigenesis. Cancer Res 72: 3445-3450, 2012.

76. Matsusaka K, Funata S, Fukayama M and Kaneda A: DNA methylation in gastric cancer, related to Helicobacter pylori and Epstein-Barr virus. World J Gastroenterol 20: 3916-3926, 2014.

77. Yau TO, Tang CM and Yu J: Epigenetic dysregulation in EpsteinBarr virus-associated gastric carcinoma: disease and treatments. World J Gastroenterol 20: 6448-6456, 2014.

78. Kusano M, Toyota M, Suzuki H, et al: Genetic, epigenetic, and clinicopathologic features of gastric carcinomas with the $\mathrm{CpG}$ island methylator phenotype and an association with EpsteinBarr virus. Cancer 106: 1467-1479, 2006.

79. Zong L and Seto Y: CpG island methylator phenotype, helicobacter pylori, Epstein-Barr virus, and microsatellite instability and prognosis in gastric cancer: a systematic review and metaanalysis. PLoS One 9: e86097, 2014

80. Okada T, Nakamura M, Nishikawa J, et al: Identification of genes specifically methylated in Epstein-Barr virus-associated gastric carcinomas. Cancer Sci 104: 1309-1314, 2013.

81. Saito M, Nishikawa J, Okada T, et al: Role of DNA methylation in the development of Epstein-Barr virus-associated gastric carcinoma. J Med Virol 85: 121-127, 2013.

82. Chapel F, Fabiani B, Davi F, et al: Epstein-Barr virus and gastric carcinoma in Western patients: comparison of pathological parameters and p53 expression in EBV-positive and negative tumours. Histopathology 36: 252-261, 2000. 
83. Matsusaka K, Kaneda A, Nagae G, et al: Classification of Epstein-Barr virus-positive gastric cancers by definition of DNA methylation epigenotypes. Cancer Res 71: 7187-7197, 2011.

84.zur Hausen A, van Grieken NC, Meijer GA, et al: Distinct chromosomal aberrations in Epstein-Barr virus-carrying gastric carcinomas tested by comparative genomic hybridization. Gastroenterology 121: 612-618, 2001.

85. Chan WY, Liu Y, Li CY, et al: Recurrent genomic aberrations in gastric carcinomas associated with Helicobacter pylori and Epstein-Barr virus. Diagn Mol Pathol 11: 127-134, 2002.

86. Chong JM, Fukayama M, Hayashi Y, et al: Microsatellite instability in the progression of gastric carcinoma. Cancer Res 54: $4595-4597,1994$.

87. Lee J, van Hummelen P, Go C, et al: High-throughput mutation profiling identifies frequent somatic mutations in advanced gastric adenocarcinoma. PLoS One 7: e38892, 2012.

88. Sukawa Y, Yamamoto $\mathrm{H}$, Nosho K, et al: Alterations in the human epidermal growth factor receptor 2-phosphatidylinositol 3-kinase-v-Akt pathway in gastric cancer. World J Gastroenterol 18: 6577-6586, 2012.

89. The Cancer Genome Atlas Research Network: Comprehensive molecular characterization of gastric adenocarcinoma. Nature 513: 202-209, 2014

90.Liang Q, Yao X, Tang S, et al: Integrative identification of epstein-barr virus-associated mutations and epigenetic alterations in gastric cancer. Gastroenterology 147: 1350-1362.e1354, 2014

91. Wang K, Kan J, Yuen ST, et al: Exome sequencing identifies frequent mutation of ARID1A in molecular subtypes of gastric cancer. Nat Genet 43: 1219-1223, 2011.

92. Abe H, Maeda D, Hino R, et al: ARID1A expression loss in gastric cancer: pathway-dependent roles with and withou Epstein-Barr virus infection and microsatellite instability. Virchows Arch 461: 367-377, 2012.

93. Moritani S, Sugihara H, Kushima R and Hattori T: Different roles of p53 between Epstein-Barr virus-positive and -negative gastric carcinomas of matched histology. Virchows Arch 440: 367-375, 2002

94. Park HY, Kang SY, Kang GH, et al: EBV infection and mismatch repair deficiency mediated by loss of hMLH1 expression contribute independently to the development of multiple synchronous gastric carcinomas. J Surg Oncol 106: 777-782, 2012.

95. Dolan DE and Gupta S: PD-1 pathway inhibitors: changing the landscape of cancer immunotherapy. Cancer Control 21 : 231-237, 2014

96. Naidoo J, Page DB and Wolchok JD: Immune modulation for cancer therapy. Br J Cancer 11: 2214-2219, 2014.

97. Marquitz AR, Mathur A, Shair KH and Raab-Traub N: Infection of Epstein-Barr virus in a gastric carcinoma cell line induces anchorage independence and global changes in gene expression. Proc Natl Acad Sci USA 109: 9593-9598, 2012.

98. Kim SY, Park C, Kim HJ, et al: Deregulation of immune response genes in patients with Epstein-Barr virus-associated gastric cancer and outcomes. Gastroenterology 148: 137-147. e139, 2014.

99. Chen BJ, Chapuy B, Ouyang J, et al: PD-L1 expression is characteristic of a subset of aggressive B-cell lymphomas and virus-associated malignancies. Clin Cancer Res 19: 3462-3473, 2013.

100.Green MR, Rodig S, Juszczynski P, et al: Constitutive AP-1 activity and EBV infection induce PD-L1 in Hodgkin lymphomas and posttransplant lymphoproliferative disorders: implications for targeted therapy. Clin Cancer Res 18: 1611-1618, 2012.

101. Kim do N and Lee SK: Biogenesis of Epstein-Barr virus microRNAs. Mol Cell Biochem 365: 203-210, 2012.

102. Pfeffer S, Zavolan M, Grasser FA, et al: Identification of virusencoded microRNAs. Science 304: 734-736, 2004.

103. Barth S, Meister G and Grasser FA: EBV-encoded miRNAs. Biochim Biophys Acta 1809: 631-640, 2011.

104. Chan JY, Gao W, Ho WK, Wei WI and Wong TS: Overexpression of Epstein-Barr virus-encoded microRNA-BART7 in undifferentiated nasopharyngeal carcinoma. Anticancer Res 32: 3201-3210, 2012.

105. Chen SJ, Chen GH, Chen YH, et al: Characterization of EpsteinBarr virus miRNAome in nasopharyngeal carcinoma by deep sequencing. PLoS One 5: e12745, 2010.
106. Choi H, Lee H, Kim SR, Gho YS and Lee SK: Epstein-Barr virus-encoded microRNA BART15-3p promotes cell apoptosis partially by targeting BRUCE. J Virol 87: 8135-8144, 2013.

107. Choy EY, Siu KL, Kok KH, et al: An Epstein-Barr virus-encoded microRNA targets PUMA to promote host cell survival. J Exp Med 205: 2551-2560, 2008.

108. Cosmopoulos K, Pegtel M, Hawkins J, et al: Comprehensive profiling of Epstein-Barr virus microRNAs in nasopharyngeal carcinoma. J Virol 83: 2357-2367, 2009.

109. Gourzones C, Gelin A, Bombik I, et al: Extra-cellular release and blood diffusion of BART viral micro-RNAs produced by EBV-infected nasopharyngeal carcinoma cells. Virol J 7: 271, 2010.

110. Gourzones C, Ferrand FR, Amiel C, et al: Consistent high concentration of the viral microRNA BART17 in plasma samples from nasopharyngeal carcinoma patients - evidence of non-exosomal transport. Virol J 10: 119, 2013.

111. Imig J, Motsch N, Zhu JY, et al: microRNA profiling in EpsteinBarr virus-associated B-cell lymphoma. Nucleic Acids Res 39: 1880-1893, 2011

112. Lung RW, Tong JH and To KF: Emerging roles of small EpsteinBarr virus derived non-coding RNAs in epithelial malignancy. Int J Mol Sci 14: 17378-17409, 2013

113. Marquitz AR, Mathur A, Nam CS and Raab-Traub N: The Epstein-Barr Virus BART microRNAs target the pro-apoptotic protein Bim. Virology 412: 392-400, 2011.

114. Motsch N, Alles J, Imig J, et al: MicroRNA profiling of Epstein-Barr virus-associated NK/T-cell lymphomas by deep sequencing. PLoS One 7: e42193, 2012.

115. Nourse JP, Crooks P, Keane C, et al: Expression profiling of Epstein-Barr virus-encoded microRNAs from paraffinembedded formalin-fixed primary Epstein-Barr virus-positive B-cell lymphoma samples. J Virol Methods 184: 46-54, 2012.

116. Riley KJ, Rabinowitz GS, Yario TA, Luna JM, Darnell RB and Steitz JA: EBV and human microRNAs co-target oncogenic and apoptotic viral and human genes during latency. EMBO J 31: 2207-2221, 2012.

117. Vereide DT, Seto E, Chiu YF, et al: Epstein-Barr virus maintains lymphomas via its miRNAs. Oncogene 33: 1258-1264, 2014

118. Wong AM, Kong KL, Tsang JW, Kwong DL and Guan XY: Profiling of Epstein-Barr virus-encoded microRNAs in nasopharyngeal carcinoma reveals potential biomarkers and oncomirs. Cancer 118: 698-710, 2011.

119. Xia T, O'Hara A, Araujo I, et al: EBV microRNAs in primary lymphomas and targeting of CXCL-11 by ebv-mir-BHRF1-3. Cancer Res 68: 1436-1442, 2008.

120.Zhu JY, Pfuhl T, Motsch N, et al: Identification of novel EpsteinBarr virus microRNA genes from nasopharyngeal carcinomas. J Virol 83: 3333-3341, 2009.

121. Qiu J and Thorley-Lawson DA: EBV microRNA BART 18-5p targets MAP3K2 to facilitate persistence in vivo by inhibiting viral replication in B cells. Proc Natl Acad Sci USA 111: 11157-11162, 2014.

122. Kim do N, Chae HS, Oh ST, et al: Expression of viral microRNAs in Epstein-Barr virus-associated gastric carcinoma. J Virol 81: 1033-1036, 2007.

123. Marquitz AR, Mathur A, Chugh PE, Dittmer DP and RaabTraub N: Expression profile of microRNAs in Epstein-Barr virus-infected AGS gastric carcinoma cells. J Virol 88: 1389-1393, 2014.

124. Kim do N, Seo MK, Choi H, et al: Characterization of naturally Epstein-Barr virus-infected gastric carcinoma cell line YCCEL1. J Gen Virol 94: 497-506, 2013.

125. Qiu J, Cosmopoulos K, Pegtel M, et al: A novel persistence associated EBV miRNA expression profile is disrupted in neoplasia. PLoS Pathog 7: e1002193, 2011.

126. Skalsky RL, Corcoran DL, Gottwein E, et al: The viral and cellular microRNA targetome in lymphoblastoid cell lines. PLoS Pathog 8: e1002484, 2012.

127. Lo AK, To KF, Lo KW, et al: Modulation of LMP1 protein expression by EBV-encoded microRNAs. Proc Natl Acad Sci USA 104: 16164-16169, 2007.

128. Barth S, Pfuhl T, Mamiani A, et al: Epstein-Barr virus-encoded microRNA miR-BART2 down-regulates the viral DNA polymerase BALF5. Nucleic Acids Res 36: 666-675, 2008.

129. Dolken L, Malterer G, Erhard F, et al: Systematic analysis of viral and cellular microRNA targets in cells latently infected with human gamma-herpesviruses by RISC immunoprecipitation assay. Cell Host Microbe 7: 324-334, 2010. 
130. Iizasa H, Wulff BE, Alla NR, et al: Editing of Epstein-Barr virus-encoded BART6 microRNAs controls their dicer targeting and consequently affects viral latency. J Biol Chem 285: 33358-33370, 2010

131. Ambrosio MR, Navari M, Di Lisio L, et al: The Epstein Barrencoded BART-6-3p microRNA affects regulation of cell growth and immuno response in Burkitt lymphoma. Infect Agent Cancer 9: 12, 2014.

132. Ramakrishnan R, Donahue H, Garcia D, et al: Epstein-Barr virus BART9 miRNA modulates LMP1 levels and affects growth rate of nasal NK T cell lymphomas. PLoS One 6: e27271, 2011.

133. Hsu CY, Yi YH, Chang KP, Chang YS, Chen SJ and Chen HC: The Epstein-Barr virus-encoded microRNA miR-BART9 promotes tumor metastasis by targeting E-cadherin in nasopharyngeal carcinoma. PLoS Pathog 10: e1003974, 2014.

134. Ross N, Gandhi MK and Nourse JP: The Epstein-Barr virus microRNA BART11-5p targets the early B-cell transcription factor EBF1. Am J Blood Res 3: 210-224, 2013.
135. Haneklaus M, Gerlic M, Kurowska-Stolarska M, et al: Cutting edge: miR-223 and EBV miR-BART15 regulate the NLRP3 inflammasome and IL-1beta production. J Immunol 189: 3795-3799, 2012.

136. Jung YJ, Choi H, Kim H and Lee SK: MicroRNA miR-BART205p stabilizes Epstein-Barr virus latency by directly targeting BZLF1 and BRLF1. J Virol 88: 9027-9037, 2014.

137. Lin TC, Liu TY, Hsu SM and Lin CW: Epstein-Barr virusencoded miR-BART20-5p inhibits T-bet translation with secondary suppression of p53 in invasive nasal NK/T-cell lymphoma. Am J Pathol 182: 1865-1875, 2013.

138. Lung RW, Tong JH, Sung YM, et al: Modulation of LMP2A expression by a newly identified Epstein-Barr virus-encoded microRNA miR-BART22. Neoplasia 11: 1174-1184, 2009. 